\title{
Characterization of Multidrug Resistant Escherichia coli Isolates Recovered from Humans and Chickens, Trinidad and Tobago
}

\author{
Sandra Ashiboe-Mensah"1, Francis Dziva ${ }^{2 *}$, Patrick Eberechi Akpaka ${ }^{1 \#, ~ C a r o l i n e ~ M l a m b o 1, ~}$ \\ Abiodun A. Adesiyun ${ }^{2}$ \\ ${ }^{1}$ Department of Paraclinical Sciences, Faculty of Medical Sciences, The University of the West Indies, St. Augustine, Trinidad and Tobago \\ ${ }^{2}$ School of Veterinary Medicine, Faculty of Medical Sciences, The University of the West Indies, St. Augustine, Trinidad and Tobago \\ Email: sashiboe@gmail.com, "peakpaka@yahoo.co.uk, carolinemlambo@gmail.com, aadesiyun@gmail.com
}

How to cite this paper: Ashiboe-Mensah, S., Dziva, F., Akpaka, P.E., Mlambo, C. and Adesiyun, A.A. (2016) Characterization of Multidrug Resistant Escherichia coli Isolates Recovered from Humans and Chickens, Trinidad and Tobago. Advances in Infectious Diseases, 6, 145-156. http://dx.doi.org/10.4236/aid.2016.64018

Received: September 19, 2016 Accepted: November 15, 2016 Published: November 18, 2016

Copyright $\odot 2016$ by authors and Scientific Research Publishing Inc. This work is licensed under the Creative Commons Attribution International License (CC BY 4.0).

http://creativecommons.org/licenses/by/4.0/ (c) (i) Open Access

\begin{abstract}
To characterize extended-spectrum beta-lactamase (ESBL) and extra-intestinal pathogenic Escherichia coli (ExPEC) associated virulence genes in E. coli isolates from chickens and humans in Trinidad and Tobago. This cross sectional study was conducted over a three-month period. A total of $471 \mathrm{E}$. coli isolates; 160 from humans treated at a regional tertiary hospital and 311 from chicken caecal samples from "pluck shops" in Trinidad \& Tobago were identified using both conventional and molecular microbiological methods. Phenotypic confirmation of ESBL producing $E$. coli isolates from humans was by Microscan system (Siemens, USA) while the double disk diffusion method was used for the chicken isolates. Polymerase chain reaction (PCR) analysis was used to determine the ESBL and ExPEC-associated virulence genes in representative human isolates and all chicken isolates. From the 311 chicken E. coli isolates, $49.2 \%$ (153/311) produced ESBL, while $56.3 \%$ (90/160) from humans were ESBL positive. All human and chicken ESBL isolates were $100 \%$ susceptible to carbapenems and aminoglycosides antimicrobials. PCR detected $21.1 \%$ bla $_{\text {Стх-м }}$, $13.3 \% \mathrm{bla}_{T E M}$ and $7.8 \% \mathrm{bla}_{\mathrm{SHV}}$ genes among $E$ coli isolates from humans compared to $0.6 \%$ bla $_{\mathrm{CTX}-\mathrm{M}}$ and $48.6 \% \mathrm{bla}_{\mathrm{TEM}}$ genes in chickens. PCR analysis revealed diverse virulence profiles among the isolates. There was a high occurrence rate of ExPEC-associated virulence genes in E. coli isolates from both humans and chickens. However, the $C T X-M-1$ genes were most predominant in humans while $T E M$ occurred in chicken isolates. The diverse ESBL and virulence associated gene profiles encountered in $E$. coli isolates from humans and chickens on the surface depicts no similarity or relationships despite occurrence in both cohort groups. Therefore E. coli strains from chickens and humans require further investigation to determine their clonal relatedness or transmission in the country.
\end{abstract}




\section{Keywords}

Extended-Spectrum Beta-Lactamase (ESBL), Escherichia coli, PCR, Virulence Genes, Trinidad \& Tobago

\section{Introduction}

Escherichia coli are common inhabitants of the gastrointestinal tract of animals and humans which exist in pathogenic and nonpathogenic (commensal) forms. Majority of pathogenic strains cause intestinal-related illnesses, but a few are implicated in extraintestinal infections in either animals or humans hence are designated as extra-intestinal pathogenic Escherichia coli (exPEC). ExPEC strains are further sub-divided into avian pathogenic Escherichia coli (APEC), which cause a systemic disease in avian species, neonatal meningitis-causing Escherichia coli (NMEC) and uropathogenic Escherichia coli (UPEC) responsible for neonatal meningitis and urinary tract infections in humans respectively. Comparative genomic studies have shown a high degree of relatedness between these ExPEC subsets [1] [2].

Published reports suggest that poultry may be a reservoir of strains causing disease in humans [3] [4] [5]. An earlier study reported that women succumbing to urinary tract infections caused by multidrug-resistant $E$. coli were significantly associated with frequent consumption of chicken products [6], providing the first direct linkage between chicken and human ExPEC infections. Subsequent studies have reported that food and chickens serve as a reservoir for E. coli causing urinary tract infections in humans [7] [8]. Poultry products (especially meat and eggs) are the most consumed protein sources in Trinidad, thus increasing the likelihood of direct or indirect transmission of bacterial pathogens from poultry to humans. The risk of transmission is further increased through rearing of chickens in the backyard further exposing many families to direct or indirect contact with chickens or their waste. Direct transmission of antibiotic-resistant $E$. coli from poultry to humans has indeed been reported in literature [9] [10]. Recent studies have shown a high degree of genetic similarities between $E$. coli strains from chicken meat, poultry and human extra-intestinal infections [11] [12] [13] [14] [15], suggesting a zoonotic transmission of such strains.

The rising global emergence of multi-drug resistant bacteria negates significant advances gained in the treatment of bacterial diseases in modern medicine. This emergence of multidrug resistant bacterial strains which has presented antibiotic resistance crisis is believed to be linked to extensive or uncontrolled use of antimicrobials in agriculture [16]. An increasingly recognized mechanism of resistance to antibiotics mediating multidrug resistance in Gram-negative bacteria including E. coli, is the production of $\beta$-lactamases, especially extended-spectrum $\beta$-lactamases (ESBLs) and $A m p C$ [17] and recently, the New Dehli Metallo-beta-lactamase-1 (NDM-1) has been reported [18].

Although extensive research has been conducted elsewhere on the prevalence of ESBLs and virulence-associated genes in ExPEC strains from humans and poultry [7] 
[19] [20], there is still a dearth of information in the Caribbean region. Although ESBL-producing bacteria including E. coli strains from humans in Trinidad \& Tobago have previously been reported [21] [22], to date, there has not been any published report on a comparative analysis of virulence-associated genes in $E$. coli isolates from humans and those from poultry especially chickens. Therefore, the current study examined if a relationship exists between $E$. coli strains from extra-intestinal infections in humans and those from chickens entering the human food pathway by characterizing ESBL subtypes and profiles of ExPEC-associated virulence genes.

\section{Materials and Methods}

\subsection{Study Design}

This cross-sectional study was conducted over a three-month period (March-May, 2014) to characterize Escherichia coli isolates from humans and chickens in Trinidad and Tobago.

\subsection{Bacterial Isolates from Humans}

Human bacterial isolates were recovered from routine clinical specimens (blood $n=60$, Cerebrospinal fluid CSF $n=12$, wound swabs $n=94$, urine $n=80$ and sputum $n=35$ ). These were processed using standard microbiological procedures (including Gram stain, culture with appropriate media, biochemical tests-catalase, coagulase, oxidase, sugar tests etc.) to conventionally identify the E. coli isolates [24]. These isolates were further analyzed with the automated microdilution machine, MicroScan WalkAway-96 System (Siemens, USA) to confirm the species and determine their minimum inhibitory concentration (MIC) values at concentrations and breakpoints recommended by the Clinical and Laboratory Standards Institute (CLSI) for antimicrobial susceptibility and ESBL screening [25]. All isolates primarily identified by the MicroScan system as ESBL producers with increased MIC breakpoints interpreted as resistant, and observed to be multidrug resistant (resistant to three or more class of antibiotics) were included in the analysis.

\subsection{Bacterial Isolates from Chickens}

Ceca of chicken samples were obtained and cultured for the isolation of $E$. coli. Isolates of $E$. coli were recovered from the samples using the following protocol. "Pluck shops", defined as a poultry processor operating from a fixed location where live poultry is converted into raw poultry products fit for human consumption, surrounding the tertiary hospital were targeted for convenience and sampling was carried out on separate occasions. Fresh chicken guts were collected from eight "pluck shops" along the EastWest corridor of Trinidad and placed in sterile sampling bags. All samples $(n=327)$ were transported to the microbiology laboratory at the School of Veterinary Science, The University of the West Indies, St. Augustine Campus in chilled containers and analysis carried out within $4 \mathrm{~h}$ of collection. The cecal sacs were separated from the interstitial material. They were aseptically opened using alcohol-sterilized scissors and an 
opening of $1-2 \mathrm{~cm}$ in diameter was made at the top wall of the cecum. Using sterile tweezers, fecal materials from the cecum were placed on MacConkey agar (Oxoid, Basingstoke, UK), ensuring as much as possible that the internal surface area of the cecum did not make contact with the agar. The inoculum was then streaked out directly on MacConkey and Blood agar plates. All plates were incubated at $37^{\circ} \mathrm{C}$ for $18-24 \mathrm{~h}$ and examined for bacterial colonies. Suspected E. coli isolates were then identified using standard methods [24]. In all 311 bacterial isolates from the 327 chicken samples were confirmed as E. coli and were included in the final analysis.

\subsection{Antimicrobial Susceptibility Testing}

Antimicrobial susceptibility testing (AST) of E. coli isolates from chickens were determined by modified Kirby Bauer disk diffusion on Muller Hinton (MH) agar against 15 antimicrobial agents according to CLSI guidelines [25]. The following antibiotics discs and concentrations were used: amoxy/clavulanic acid $(30 \mu \mathrm{g})$, cefotaxime $(30 \mu \mathrm{g})$, ceftazidime $(30 \mu \mathrm{g})$, cefoxitin $(30 \mu \mathrm{g})$, cefpodoxime $(10 \mu \mathrm{g})$, entapenem $(10 \mu \mathrm{g})$, imipenem $(10 \mu \mathrm{g})$, meropenem $(10 \mu \mathrm{g})$ ciprofloxacin $(5 \mu \mathrm{g})$, norfloxacin $(10 \mu \mathrm{g})$, Amikacin, (30 $\mu \mathrm{g})$, sulphamethoxazole/trimethoprim $(25 \mu \mathrm{g})$, gentamicin $(10 \mu \mathrm{g})$ and tetracycline (30 $\mu \mathrm{g}$ ) (all from Oxoid, Basingstoke, UK). To determine the susceptibility of the $E$. coli isolates to the antimicrobial agents, pure colony were suspended in phosphate-buffer to a 0.5 McFarland turbidity standard and then streaked on $\mathrm{MH}$ agar plates. Excess inoculum was aseptically removed, and the agar plates allowed to dry before dispensing antibiotic discs. After overnight incubation at $35^{\circ} \mathrm{C}$ temperature, plates were examined for zones of inhibition and diameters were measured using a caliper. Interpretation of the zones of inhibition was done as stipulated by the Clinical and Laboratory Standards Institute (CLSI, 2014). Escherichia coli ATCC 25,922 strain was used for quality control.

\subsection{Confirmation of ESBL Phenotypes in Chicken Isolates}

ESBL phenotypes were confirmed by using $30 \mu \mathrm{g}$ amoxicillin-clavulanic acid disc surrounded by discs of $30 \mu \mathrm{g}$ ceftazidime, cefotaxime and cefotixin at a distance of $15 \mathrm{~mm}$ on $\mathrm{MH}$ agar plate inoculated according to standard procedures and CLSI guidelines [25]. After overnight incubation at $37^{\circ} \mathrm{C}$, any enhancement of the zone of inhibition between a $\beta$-lactam disc and a disc containing the $\beta$-lactamase inhibitor was indicative of the presence of ESBL.

The following CLSI ESBL screening cut-off values were used for third-generation cephalosporins: cefpodoxime $(10 \mu \mathrm{g} / \mathrm{disk}) \leq 17 \mathrm{~mm}$; ceftazidime $(30 \mu \mathrm{g} / \mathrm{disk}) \leq 17 \mathrm{~mm}$; cefotaxime $(30 \mu \mathrm{g} / \mathrm{disk}) \leq 22 \mathrm{~mm}$; and ceftriaxone $(30 \mu \mathrm{g} / \mathrm{disk}) \leq 19 \mathrm{~mm}$ [25]. E. coli ATCC 25,922 strain was used as a negative ESBL control. Each confirmed isolate by these conventional microbiological tests was stored in brain heart infusion broth with $15 \%(\mathrm{v} / \mathrm{v})$ glycerol at $-20^{\circ} \mathrm{C}$ until subjected to further molecular analysis.

\subsection{Molecular Analysis}

All E. coli isolates from chicken $(\mathrm{n}=311)$ were subjected to molecular analysis for 
ESBL genes while only multidrug resistant phenotypically confirmed as ESBL producers by the automated system in humans $(\mathrm{n}=90)$ were only subjected to molecular analysis for the presence of the ESBL genes: TEM, SHV, CTX-M group $1 \& 2, C M Y-2$ and $A m p C$ using PCR tool as previously described [20]. Oligonucleotide primers used in this study and their respective annealing temperatures are listed in Table 1 . The reaction mixture consisted of the following: $12.5 \mu \mathrm{l} \mathrm{GoTaq}^{\circledR}$ Green Master Mix (Pro-

Table 1. Oligonucleotide primers used in the analysis of ESBLs and virulence-associated genes in Escherichia coli isolates from humans and chickens, Trinidad and Tobago.

\begin{tabular}{|c|c|c|c|c|}
\hline Gene & Primer name & Sequence ( $5^{\prime}$ to $\left.3^{\prime}\right)$ & Annealing $\mathrm{T}\left({ }^{\circ} \mathrm{C}\right)$ & Reference \\
\hline \multicolumn{5}{|l|}{ ESBLs } \\
\hline \multirow{2}{*}{$b^{\prime} a_{\mathrm{SHV}}$} & SHV-F & TTATCTCCCTGTTAGCCACC & \multirow{2}{*}{58} & \multirow{2}{*}{ [19] } \\
\hline & SHV-R & GATTTGCTGATTTCGCTCGG & & \\
\hline \multirow[b]{2}{*}{$b l a_{\mathrm{TEM}}$} & TEM-F & GCGGAACCCCTATTTG & \multirow[b]{2}{*}{55} & \multirow[b]{2}{*}{ [19] } \\
\hline & TEM-R & ACCAATGCTTAATCAGTGAG & & \\
\hline \multirow{2}{*}{ bla $_{\mathrm{CTX}-\mathrm{M} 1}$} & CTX-M 1-F & GGTTAAAAAATCACTGCGTC & \multirow{2}{*}{56} & \multirow{2}{*}{ [19] } \\
\hline & CTX-M1-R & TTGGTGACGATTTTAGCCGC & & \\
\hline \multirow{2}{*}{ bla $_{\mathrm{CTX}-\mathrm{M} 2}$} & CTX-M2-F & GATGAGACCTTCCGTCTGGA & \multirow{2}{*}{61} & \multirow{2}{*}[19]{} \\
\hline & CTX-M2-R & CAGAAACCGTGGGTTACGAT & & \\
\hline \multirow{2}{*}{$b l a_{\mathrm{CMY}-2}$} & CMY-2 F & ATGATGAAAAAATCGTTATGCTGC & \multirow{2}{*}{62} & \multirow{2}{*}{ [19] } \\
\hline & CMY-2 R & GCTTTTCAAGAATGCGCCAGG & & \\
\hline \multirow{2}{*}{$A m p C$} & AmpC-F & ATGATGAAAAAATCGTTATGC & \multirow{2}{*}{56} & \multirow{2}{*}{ [19] } \\
\hline & AmpC-R & TTGCAGCTTTTCAAGAATGCGC & & \\
\hline \multicolumn{5}{|c|}{ ExPEC-associated virulence genes } \\
\hline \multirow{2}{*}{$\operatorname{fim} C$} & fim $C-F$ & TAAGGAAATCGCAGGAA & \multirow{2}{*}{52.0} & \multirow{2}{*}[20]{} \\
\hline & fim $C-R$ & GTCAGGTAATAGGGTGTCG & & \\
\hline \multirow{2}{*}{$o m p A$} & $o m p A-F$ & TTTTGGATGATAACGAGG & \multirow{2}{*}{50.0} & \multirow{2}{*}[20]{} \\
\hline & $o m p A-R$ & TGCTGGGTAAGGAATAAC & & \\
\hline \multirow[b]{2}{*}{ bet $A$} & bet $A-F$ & CGGTTTCGGCGTGGTTAC & \multirow[b]{2}{*}{60.0} & \multirow[b]{2}{*}[20]{} \\
\hline & bet $A-R$ & GTGGGCATGTGCGGATTA & & \\
\hline \multirow{2}{*}{$i b e A$} & $i b e A-F$ & AGGCAGGTGTGCGCCGCGTAC & \multirow{2}{*}{58.0} & \multirow{2}{*}[20]{} \\
\hline & $i b e A-R$ & TGGTGCTCCGGCAAACCATGC & & \\
\hline$r f a H$ & $r f a H-F$ & TGTATCGCAACACGCACG & 540 & {$[20]$} \\
\hline & $r f a H-R$ & AAAACCAGTCGAGCCTTC & & \\
\hline irp2 & $\operatorname{irp} 2-F$ & AAGGATTGCCTGTTACCGGAC & 520 & {$[20]$} \\
\hline & $\operatorname{irp} 2-R$ & TCGTCGGGCAGCGTTTCTTCT & & \\
\hline$f_{U}$ & fуи $A-F$ & GCTTTATCCTCTGGCCTT & 520 & {$[50]$} \\
\hline tgen & fyuA-R & GGCATATTGACGATTAAC & 0.0 & {$[20]$} \\
\hline
\end{tabular}

$\mathrm{T}=$ Temperature; Reference $=$ Reference cited . 
mega, Madison, WI), $2 \mu \mathrm{l}$ of each primer (forward and reverse) and small portion of colony as source of template DNA, made to $25 \mu \mathrm{l}$ with nuclease-free water. The PCR cycling reaction comprised the following: an initial denaturation step at $94^{\circ} \mathrm{C}$ for $5 \mathrm{~min}$, followed by 25 cycles of $94^{\circ} \mathrm{C}$ for $30 \mathrm{sec}$, annealing at specified temperature for $45 \mathrm{~s}$, extension for $1 \mathrm{~min}$ and then a single final extension at $72^{\circ} \mathrm{C}$ for $5 \mathrm{~min}$. Amplicons (5 $\left.\mu \mathrm{l}\right)$ were resolved on $1 \%$ agarose gel in $1 \times$ Tris-Acetate-EDTA (TAE) buffer alongside a 100 bp ladder (New England Biolabs, Ipswich, MA) and viewed on a UV trans-illuminator after staining with Gelred ${ }^{\mathrm{TM}}$ dye (Biotium Inc., Hayward, CA). The validity of the representative amplicons was ascertained by DNA sequencing. Resolved amplicons were purified of agarose gel using a Qiagen gel extraction kit, cloned into TOPO vector (Life Technologies, Sao Paulo, Brazil) and then submitted to Macrogen Korea (Seoul, South Korea) for sequencing. Sequences were confirmed with BLAST analysis at the National Centre of Biotechnology Information website (http://www.ncbi.nlm.nih.gov/BLAST).

\subsection{Virulence Genotyping}

Representative ESBL-producing E. coli isolates from both humans $(\mathrm{n}=42)$ and chickens $(n=45)$ were subjected to PCR analysis for a panel of ExPEC-associated virulence genes as previously reported with slight modifications [3] [19] [20]. These genes include: irp2 (iron-repressible protein), fyuA (yersiniabactin synthesis), ibeA (invasion of brain endothelium), betA (choline dehydrogenase), rfaH (a transcriptional anti-terminator), fimC (type 1 fimbriae) and OmpA (outer membrane protein A). Oligonucleotide primers used in this study, target genes and their respective annealing temperatures are listed in Table 1. PCR amplification and subsequent detection of amplicons were performed as described above. A 100 bp DNA ladder was used as a molecular size marker.

\subsection{Statistical Analysis}

Frequencies of ESBL and ExPEC-associated virulence genes were calculated using Epi info $^{\text {tw }}$ and Microsoft Excel. Chi-squared test and Fisher's exact test were used as appropriate to compare data from different groups. Data were reported as comparisons of frequency distributions and a $\mathrm{p}$-value $<0.05$ was considered statistically significant.

\subsection{Ethical Approval}

The study was approved by the Ethics Committee of the University of the West Indies, St. Augustine Campus.

\section{Results}

A total of $471 E$. coli isolates (humans $\mathrm{n}=160$, chickens $\mathrm{n}=311$ ) were included in the final analysis. Although not shown, the antimicrobial susceptibility of $E$. coli isolates from both humans and chickens revealed that all (100\%) were susceptible to tested carbapenems and aminoglycosides agents. E. coli isolates from humans (54\%) were resistant to tested cephalosporins while cefotixin showed the highest susceptibility (78\%), the least was cefotaxime (40\%). Isolates from chickens on the other hand exhibited over 
$95 \%$ susceptibility to all the cephalosporins. There was resistance $(>45 \%)$ in amoxycillin/clavulanate, tetracyclines, fluoroquinolones and sulphamethoxazole/trimethoprim in E. coli isolates from both humans and chickens.

More than half of analyzed isolates $51.6 \%$ (243/471) were ESBL producers (humans $56.2 \%, 90 / 160$; chickens $49.2 \%, 153 / 311 ; \mathrm{p}=0.8)$. As depicted in Table 2, the predominant ESBL gene encountered among $E$. coli isolates recovered from chickens was $48.6 \%$ TEM compared to $13.3 \%$ from humans $(\mathrm{p}<0.01)$. No single $C M Y-2, S H V, A m p C$ or even their combined genes was recovered from $E$. coli isolates from the chickens. Despite the high frequency of TEM ESBL genes among E. coli isolates from the chickens, there was only a paltry $0.6 \%$ occurrence of CTX-M- 1 gene. All ESBL genes assayed for were not detected in $50.8 \%$ and $11.1 \%$ of isolates from chickens and humans, respectively. The difference was statistically significant $(\mathrm{p}<0.01)$.

E. coli isolates with co-existing CTX-M-1 and CTX-M-2 genes, tested negative for all the virulence genes among chicken isolates. This pattern was also observed in the isolate with the $C M Y-2$ gene only. The frequency of distribution of ExPEC-associated virulence genes in human and chicken isolates are shown in Table 3. All TEM-positives E. coli isolates from chicken samples lacked the irp2 gene which was predominant in isolates from humans. ibe $A$ was also absent in isolates from chickens, but was present

Table 2. Distribution of genes among ESBL-producing E. coli isolates recovered from humans and chickens, Trinidad and Tobago (\%).

\begin{tabular}{ccc}
\hline blagenes & Humans $(\mathrm{n}=90)$ & Chickens $(\mathrm{n}=311)$ \\
TEM & $12(13.3)$ & $151(48.6)$ \\
CTX-M-1 & $19(21.1)$ & $2(0.6)$ \\
CMY-2 & $6(6.7)$ & $0(0.0)$ \\
SHV & $7(7.8)$ & $0(0.0)$ \\
CTX-M-1 CTX-M-2 & $6(6.7)$ & $0(0.0)$ \\
CMY-2 AmpC & $5(5.5)$ & $0(0.0)$ \\
TEM CTX-M-1 & $25(27.8)$ & $0(0.0)$ \\
NEGATIVE & $10(11.1)$ & $158(50.8)$ \\
\hline
\end{tabular}

Table 3. Occurrence of virulence genes in representative ESBL-producing E. coli isolates recovered from humans and chickens, Trinidad and Tobago (\%).

\begin{tabular}{cccc}
\hline Virulence factor genes & Humans $(\mathrm{n}=42)$ & Chickens $(\mathrm{n}=45)$ & p-value \\
\hline fimC & $27(64.3)$ & $27(60.0)$ & 1.000 \\
ompA & $33(78.6)$ & $45(100.0)$ & 1.000 \\
rfaH & $36(85.7)$ & $6(13.3)$ & 0.002 \\
irp2 & $33(78.6)$ & $0(0.0)$ & $<0.01$ \\
betA & $36(85.7)$ & $36(80.0)$ & 1.000 \\
fyuA & $33(78.6)$ & $12(26.7)$ & 0.002 \\
ibeA & $9(21.4)$ & $0(0.0)$ & $<0.01$ \\
\hline
\end{tabular}


in nine isolates from humans harboring TEM, CTX-M1, CMY-2 and $A m p C$ genes.

The gene omp $A$ was the most frequent (100\%) virulence gene in chicken isolates, followed by bet $A(80 \%)$ and fim $C(60 \%)$. None of the chicken isolates possessed irp 2 and $i b e A$. In contrast, both $r f a H$ and bet $A$ had distribution frequency of $85.7 \%$, followed by irp2, fyuA and omp $A$ at 78.6\%, fimC (64.3\%) and ibeA (21.4\%). Genes $r f a H$, irp2, fyu $A$ and $i b e A$ were detected at statistically significantly higher frequencies in isolates from human isolates than ones from chicken $(\mathrm{p}<0.05)$. The occurrences of bet $A$, fim $C$, and omp $A$ were similar between the human and chicken isolates, whereas irp2 and $i b e A$ genes were only detected in human isolates.

\section{Discussions}

This study was designed to characterize the ESBL subtypes and profiles of ExPEC associated virulence genes among $E$. coli strains from humans and those from chickens that could enter the human food pathway in Trinidad and Tobago.

The antimicrobial susceptibility of each group (humans and chickens) revealed that all were susceptible to tested carbapenems and aminoglycosides agents. This is an important finding in the country because the option still exists for use of these class of antimicrobial agents in both humans and agricultural health sectors. Most E. coli isolates from humans were resistant to more than half of the tested cephalosporins (54\%) while those from chickens exhibited over $95 \%$ susceptibility to all the cephalosporins. This does not seem to support any evidence of transfer from chickens to humans which again is suggestive of the absence of zoonotic spread E. coli strains resistance to this class of antimicrobial agents between chickens and humans in the country [26].

Generally it was observed that $E$. coli isolates recovered from humans (88.9\%) carried more of the ESBL genes than those from chickens (49.2\%), again suggesting a less likelihood of transfer of such genes from chickens to humans in the country.

The TEM genes in this analysis were observed to be predominant among E. coli isolates from chicken (48.6\%) as opposed to the frequency in isolates from humans (13\%). A similar predominance of TEM genes has also been reported in China and Belgium [27] [28] [29] among E. coli isolates from both chickens and humans. TEM is the most common ESBL found worldwide, and therefore its occurrence in chicken isolates was not surprising. Although the TEM genes are not classified as ESBL but they have been noted to confer ESBL properties [30].

Another major finding was that $C T X-M-1$ was the most prevalent among ESBLproducing isolates from humans and this is in agreement with a previous study conducted in this institution [23]. Such a high predominance of $C T X-M$ group 1 alleles has also been previously reported among clinical isolates elsewhere [31]. In this current study, there appears to be no likelihood of acquisition of the CTX-M group genes from E. coli isolates recovered from chickens since the frequency of these genes was very low or nonexistent in the chicken samples. This is in contrast to reports elsewhere where these have been recovered [32] [33]. Further studies however need to be carried out to determine if there was any clonal similarity or relatedness between the few that was 
seen in the chicken isolates with ones from humans.

Except for $i b e A$ and irp2 genes that were not detected among the $E$. coli isolates from chicken samples in this study, all the other ExPEC-associated virulence genes were detected in high frequencies in isolates from both humans and chicken specimens. These ExPEC-associated virulence genes were selected on the basis of having been previously used in studying isolates from poultry and humans; and also of being known to be located on high pathogenicity island of E. coli strains that are pathogenic to humans [19] [20] [34]. The functions and distribution frequencies of other ExPEC-associated virulence genes in poultry $E$. coli isolates have previously been reported in literature [34] [35]. The high rate of detection of these genetic profiles especially the fim $C$, ompA, bet $A$ and fyuA observed in $E$. coli isolates from both humans and chickens strongly imply relationship between them. Such demonstration of high frequency of genetic profiles in ExPEC-associated virulence genes between ESBL-positive human and chicken isolates could mean their genetic relatedness. This definitely needs further molecular studies such as finger printing analysis to draw a conclusive statement.

A major limitation of this study was our inability to use any fingerprinting methods such as pulsed field gel electrophoresis (PFGE) or multi locus sequence typing (MLST) to delineate the genetic relatedness of the $E$. coli isolates from humans and the chickens.

\section{Conclusion}

Despite the limitation in the design of this analysis, the findings of this study revealed that the $T E M$ gene was the predominant ESBL in chickens and the $C T X-M-1$ group was most prevalent in isolates from humans. There was no carbapenem and aminoglycosides resistance in the $E$. coli isolates from both humans and chickens. Analysis of the ExPEC-associated virulence profiles clearly demonstrates high occurrence rate in isolates from humans and chickens suggesting a probability of similarity in both cohort groups. Further studies are still needed to delineate this trend.

\section{Acknowledgements}

Authors wish to thank the Caribbean Public Health Agency (CARPHA) for financial support (awarded to FD).

\section{References}

[1] Ewers, C., Li, G., Wilking, H., Kiessling, S., Alt, K., Antao, E.M., et al. (2007) Avian Pathogenic, Uropathogenic, and Newborn Meningitis-Causing Escherichia coli: How Closely Related Are They? International Journal of Medical Microbiology, 297, 163-176. http://dx.doi.org/10.1016/j.ijmm.2007.01.003

[2] Johnson, T.J., Kariyawasam, S., Wannemuehler, Y., Mangiamele, P., et al. (2007) The Genome Sequence of Avian Pathogenic Escherichia coli Strain O1:K1:H7 Shares Strong Similarities with Human Extra-Intestinal Pathogenic E. coli Genomes. Journal of Bacteriology, 189, 3228-3236. http://dx.doi.org/10.1128/JB.01726-06

[3] Ewers, C., Antão, E.M., Diehl, I., Philipp, H.C. and Wieler, L.H. (2009) Intestine and Envi- 
ronment of the Chicken as Reservoirs for Extra-Intestinal Pathogenic Escherichia coli Strains with Zoonotic Potential. Applied and Environmental Microbiology, 75, 184-192.

http://dx.doi.org/10.1128/AEM.01324-08

[4] Mora, A., Viso, S., López, C., Alonso, M.P., García-Garrote, F., Dabhi, G., Mamani, R., Herrera, A., Marzoa, J., Blanco, M., Blanco, J.E., Moulin-Schouleur, M., Schouler, C. and Blanco, J. (2013) Poultry as Reservoir for Extraintestinal Pathogenic Escherichia coli O45:K1: H7-B2-ST95 in Humans. Veterinary Microbiology, 167, 506-512.

http://dx.doi.org/10.1016/j.vetmic.2013.08.007

[5] Mellata, M. (2013) Human and Avian Extraintestinal Pathogenic Escherichia coli: Infections, Zoonotic Risks, and Antibiotic Resistance Trends. Foodborne Pathogens and Disease, 10, 916-932. http://dx.doi.org/10.1089/fpd.2013.1533

[6] Manges, A.R., Smith, S.P., Lau, B.J., Nuval, C.J., Eisenberg, J.N., Dietrich, P.S. and Riley, L.W. (2007) Retail Meat Consumption and the Acquisition of Antimicrobial Resistant Escherichia coli Causing Urinary Tract Infections: A Case-Control Study. Foodborne Pathogens and Disease, 4, 419-431. http://dx.doi.org/10.1089/fpd.2007.0026

[7] Bergeron, C.R., Prussing, C., Boerlin, P., Daignault, D., Dutil, L., Reid-Smith, R.J., Zhanel, G.G. and Manges, A.R. (2012) Chicken as Reservoir for Extraintestinal Pathogenic Escherichia coli in Humans, Canada. Emerging Infectious Diseases, 18, 415-421.

http://dx.doi.org/10.3201/eid1803.111099

[8] Vincent, C., Boerlin, P., Daignault, D., Dozois, C.M., Dutil, L., Galanakis, C., Reid-Smith, R.J., Tellier, P.P., Tellis, P.A., Ziebell, K. and Manges, A.R. (2010) Food Reservoir for Escherichia coli Causing Urinary Tract Infections. Emerging Infectious Diseases, 16, 88-95. http://dx.doi.org/10.3201/eid1601.091118

[9] Ojeniyi, A.A (1989). Direct Transmission of Escherichia coli from Poultry to Humans. Epidemiology \& Infection, 103, 513-522. http://dx.doi.org/10.1017/S0950268800030910

[10] Linton, A.H., Howe, K., Bennett, P.M., Richmond, M.H. and Whiteside, E.J. (1977) The Colonization of the Human Gut by Antibiotic Resistant Escherichia coli from Chickens. Journal of Applied Bacteriology, 43, 465-469. http://dx.doi.org/10.1111/j.1365-2672.1977.tb00773.x

[11] Overdevest, I., Willemsen, I., Rijnsburger, M., Eustace, A., Xu, L., Hawkey, P., Heck, M., Savelkoul, P., Vandenbroucke-Grauls, C., van der Zwaluw, K., Huijsdens, X. and Kluytmans, J. (2011) Extended-Spectrum $\beta$-Lactamase Genes of Escherichia coli in Chicken Meat and Humans, The Netherlands. Emerging Infectious Diseases, 17, 1216-1222.

http://dx.doi.org/10.3201/eid1707.110209

[12] Leverstein-van Hall, M.A., Dierikx, C.M., Cohen Stuart, J., Voets, G.M., van den Munckhof, M.P., van Essen-Zandbergen, A., et al. (2011) Dutch Patients, Retail Chicken Meat and Poultry Share the Same ESBL Genes, Plasmids and Strains. Clinical Microbiology and Infection, 17, 873-880. http://dx.doi.org/10.1111/j.1469-0691.2011.03497.x

[13] Kluytmans, J.A., Overdevest, I.T., Willemsen, I., Kluytmans-van den Bergh, M.F., van der Zwaluw, K., Heck, M., Rijnsburger, M., Vandenbroucke-Grauls, C.M., Savelkoul, P.H., Johnston, B.D., Gordon, D. and Johnson, J.R. (2013) Extended-Spectrum $\beta$-Lactamase-Producing Escherichia coli from Retail Chicken Meat and Humans: Comparison of Strains, Plasmids, Resistance Genes, and Virulence Factors. Clinical Infectious Diseases, 56, 478-487. http://dx.doi.org/10.1093/cid/cis929

[14] Voets, G.M., Fluit, A.C., Scharringa, J., Schapendonk, C., van den Munckhof, T., Leverstein-van Hall, MA. and Stuart, J.C. (2013) Identical Plasmid AmpC Beta-Lactamase Genes and Plasmid Types in E. coli Isolates from Patients and Poultry Meat in the Netherlands. International Journal of Food Microbiology, 167, 359-362. 
http://dx.doi.org/10.1016/j.ijfoodmicro.2013.10.001

[15] Jakobsen, L., Kurbasic, A., Skjøt-Rasmussen, L., Ejrnaes, K., Porsbo, L.J., Pedersen, K., Jensen, L.B., Emborg, H.D., Agersø, Y., Olsen, K.E., Aarestrup, F.M., Frimodt-Møller, N. and Hammerum, A.M. (2010) Escherichia coli Isolates from Broiler Chicken Meat, Broiler Chickens, Pork, and Pigs Share Phylogroups and Antimicrobial Resistance with Community-Dwelling Humans and Patients with Urinary Tract Infection. Foodborne Pathogens and Disease, 7, 537-547. http://dx.doi.org/10.1089/fpd.2009.0409

[16] Ventola, C.L (2015) The Antibiotic Resistance Crisis: Part 1-Causes and Threats. Pharmacy and Therapeutics, 40, 277-283.

[17] Hanson, N.D., Thomson, K.S., Moland, E.S., Sanders, C.C., Berthold, G. and Penn, R.G (1999) Molecular Characterization of a Multiply Resistant Klebsiella pneumoniae Encoding ESBLs and a Plasmid-Mediated AmpC. Journal of Antimicrobial Chemotherapy, 44, 377 380. http://dx.doi.org/10.1093/jac/44.3.377

[18] Kumarasamy, K.K., Toleman, M.A., Walsh, T.R., Bagaria, J., Butt, F., Balakrishnan, R., Chaudhary, U., Doumith, M., et al. (2010) Emergence of a New Antibiotic Resistance Mechanism in India, Pakistan, and the UK: A Molecular, Biological, and Epidemiological Study. Lancet Infectious Diseases, 10, 597-602.

http://dx.doi.org/10.1016/S1473-3099(10)70143-2

[19] Doi, Y., Paterson, D.L., Egea, P., Pascual, A., López-Cerero, L., Navarro, M.D., AdamsHaduch, J.M., Qureshi, Z.A., Sidjabat, H.E. and Rodríguez-Baño, J. (2010) Extended-Spectrum and CMY-Type Beta-Lactamase-Producing Escherichia coli in Clinical Samples and Retail Meat from Pittsburgh, USA and Seville, Spain. Clinical Microbiology and Infection, 16, 33-38. http://dx.doi.org/10.1111/j.1469-0691.2009.03001.x

[20] Nandanwar, N., Janssen, T., Kühl, M., Ahmed, N., Ewers, C. and Wieler, L.H. (2014) Extraintestinal Pathogenic Escherichia coli (ExPEC) of Human and Avian Origin Belonging to Sequence Type Complex 95 (STC95) Portray Indistinguishable Virulence Features. International Journal of Medical Microbiology, 304, 835-842. http://dx.doi.org/10.1016/j.ijmm.2014.06.009

[21] Cherian, B.P., Singh, N., Charles, W. and Prabhakar, P. (1999) Extended Spectrum $\beta$-Lactamase Producing Salmonella enteritidis in Trinidad \& Tobago. Emerging Infectious Diseases, 5, 181-182. http://dx.doi.org/10.3201/eid0501.990128

[22] Akpaka, P.E. and Swanston, W.H. (2008) Phenotypic Detection and Occurrence of Extended-Spectrum Beta-Lactamases in Clinical Isolates of Klebsiella pneumoniae and Escherichia coli at a Tertiary Hospital in Trinidad \& Tobago. Brazilian Journal of Infectious Diseases, 12, 516-520. http://dx.doi.org/10.1590/\$1413-86702008000600014

[23] Akpaka, P.E., Legall, B. and Padman, J. (2010) Molecular Detection and Epidemiology of Extended-Spectrum Beta-Lactamase Genes Prevalent in Clinical Isolates of Klebsiella pneumoniae and E. coli from Trinidad and Tobago. West Indian Medical Journal, 59, 591596.

[24] Nataro, J.P., Bopp, C.A., Fields, P.I., Kaper, J.B. and Strockbine, N.A. (2007) Escherichia, Shigella and Salmonella. Manual of Clinical Microbiology. 9th Edition, SM Press, Washington DC, 670-687.

[25] Clinical and Laboratory Standards Institute (2014) Performance Standards for Antimicrobial Susceptibility Testing. 21st Informational Supplement, M100-S24, Clinical and Laboratory Standards Institute, Wayne.

[26] Kissoon, S., Akpaka, P.E. and Swanston, W.H. (2015) Vancomycin Resistant Enterococci Infections in Trinidad and Tobago. British Microbiology Research Journal, 9, 20-28. http://dx.doi.org/10.9734/BMRJ/2015/18531 
[27] Wang, Y., Ho, T., Han, J., Wang, J., Foley, S.L., et al. (2012) Prevalence of ESBLs and PMQR Genes in Fecal Escherichia coli Isolated from the Non-Human Primates in Six Zoos in China. Veterinary Microbiology, 159, 53-59.

http://dx.doi.org/10.1016/j.vetmic.2012.03.009

[28] Yuan, L., Liu, J.-H., Hu, G.-Z., Pan, Y.-S., Liu, Z.-M., Mo, J. and Wei, Y.-J. (2009) Molecular Characterization of Extended-Spectrum $\beta$-Lactamase-Producing Escherichia coli Isolates from Chickens in Henan Province, China. Journal of Medical Microbiology, 58, 1449-1453. http://dx.doi.org/10.1099/jmm.0.012229-0

[29] Smet, A., Martel, A., Persoons, D., Dewulf, J., Heyndrickx, M., Catry, B., Herman, L., Haesebrouck, F. and Butaye, P. (2008) Diversity of Extended-Spectrum $\beta$-Lactamases and Class C $\beta$-Lactamases among Cloacal Escherichia coli Isolates in Belgian Broiler Farms. Antimicrobial Agents and Chemotherapy, 52, 1238-1243. http://dx.doi.org/10.1128/AAC.01285-07

[30] Paterson, D.L. and Bonomo, R.A. (2005) Extended-Spectrum Beta Lactamases: A Clinical Update. Clinical Microbiology Reviews, 18, 657-686.

http://dx.doi.org/10.1128/CMR.18.4.657-686.2005

[31] Woodford, N., Fagan, E.J. and Ellington, M.J. (2006) Multiplex PCR for Rapid Detection of Genes Encoding CTX-M Extended-Spectrum $\beta$-Lactamases. Journal of Antimicrobial Chemotherapy, 57, 154-155. http://dx.doi.org/10.1093/jac/dki412

[32] Kawamura, K., Goto, K., Nakane, K. and Arakawa, Y. (2014) Molecular Epidemiology of Extended-Spectrum $\beta$-Lacatamases and Escherichia coli Isolated from Retail Foods Including Chicken Meat in Japan. Foodborne Pathogens and Disease, 11, 104-110. http://dx.doi.org/10.1089/fpd.2013.1608

[33] Xi, M., Wu, Q., Wang, X., Yang, B., Xia, X. and Li, D. (2015) Characterization of ExtendedSpectrum $\beta$-Lactamase-Producing Escherichia coli Strains Isolated from Retail Foods in Shaanxi Province, China. Journal of Food Protection, 78, 1018-1023. http://dx.doi.org/10.4315/0362-028X.JFP-14-490

[34] Wang, Y., Tang, C., Yu, X., Xia, M. and Yue, H. (2010) Distribution of Serotypes and Virulence-Associated Genes in Pathogenic Escherichia coli Isolated from Ducks. Avian Pathology, 39, 297-302. http://dx.doi.org/10.1080/03079457.2010.495742

[35] Dierikx, C., van Essen-Zandbergen, A., Veldman, K., Smith, H. and Mevius, D. (2010) Increased Detection of Extended Spectrum Beta-Lactamase Producing Salmonella enterica and Escherichia coli Isolates from Poultry. Veterinary Microbiology, 145, 273-278. http://dx.doi.org/10.1016/j.vetmic.2010.03.019 
Submit or recommend next manuscript to SCIRP and we will provide best service for you:

Accepting pre-submission inquiries through Email, Facebook, LinkedIn, Twitter, etc. A wide selection of journals (inclusive of 9 subjects, more than 200 journals)

Providing 24-hour high-quality service

User-friendly online submission system

Fair and swift peer-review system

Efficient typesetting and proofreading procedure

Display of the result of downloads and visits, as well as the number of cited articles

Maximum dissemination of your research work

Submit your manuscript at: http://papersubmission.scirp.org/

Or contact aid@scirp.org 